\title{
Cristalização de melão pelo processo lento de açucaramento
}

\author{
Crystallization of melon fruit through slow sugary process
}

\author{
Ângelo Shigueyuki Morita ${ }^{1}$ Vilson Alves de Gois ${ }^{2}$ Everardo Ferreira Praça ${ }^{3}$ \\ José Celesmário Tavares ${ }^{4}$ Jean Carlos de Andrade $^{5}$ Franciscleudo Bezerra da Costa $^{6}$ \\ Aurélio Paes Barros Júnior ${ }^{7}$ Adalberto Hipólito de Sousa ${ }^{8}$
}

RESUMO

Este trabalho foi conduzido no laboratório de Tecnologia de Alimentos da Escola Superior de Agricultura de Mossoró (ESAM). Avaliou-se a possibilidade de processar o melão como fruta cristalizada. Foram testadas as variedades Gália, Pele de Sapo e Orange Fresh, utilizando-se o processo lento de açucaramento, retirandose as polpas em formas de bolas e colocando-as sucessivamente em soluções de sacarose a 20,30, 40, 50, 60 e $70^{\circ}$ Brix até abrir a fervura, mantendo-se a polpa em repouso por 24 horas a cada solução de sacarose. Em seguida, os frutos foram colocados em uma estufa a $50^{\circ} \mathrm{C}$ durante 6 horas, atingindo-se assim, a umidade final entre 26,16 a 27,53\%. Foram determinados teor de umidade, $\mathrm{pH}$, sólidos solúveis totais, e os produtos submetidos a uma análise sensorial. Constatou-se que a cristalização em melão foi tecnicamente viável, que a variedade Pele de Sapo foi a melhor aceita, e que não houve mudança na coloração da polpa das variedades.

Palavras-chave: Cucumis melo L., processamento, conservação, desidratação osmótica.

\begin{abstract}
The experiment was carried out in the Food Technology Laboratory of the Escola Superior de Agricultura de Mossoró (ESAM), Mossoró-RN, Brazil to evaluate the possibility of processing the melon pulp as a crystallized fruit by using the us following melon varieties: Gália, Pele de Sapo, and Orange Flesh, utilizing the slow sugary process. The pulps were withdrawn in little ball form and put successively into sucrose solutions at $20,30,40,50,60$ and $70^{\circ} \mathrm{Brix}$, until boiling, keeping them in inactivity for 24 hours in each solution. After that, the fruits were placed in a stove at $50^{\circ} \mathrm{C}$ during 6 hours, reaching final humidity between 26.16 and $27.53 \%$. Evaluations for humidity content, $\mathrm{pH}$ and total soluble solids were made. In addition a sensorial analysis was made. It was observed that the melon crystallization was technically feasible. Pele de Sapo melon was the best in comparison to the other types. Changing in the melon pulp colouring was not observed.
\end{abstract}

Key words: Cucumis melo L., processing, conservation, osmotic dehydration.

${ }^{1}$ Engenheiro Agrônomo, Departamento de Química, Escola Superior de Agricultura de Mossoró (ESAM), Brasil. Email: angeloshigueyuki@hotmail.com.

${ }^{2}$ Engenheiro Agrônomo, Professor Adjunto, Departamento de Química, ESAM, Brasil. E-mail: Vilson@esam.br. ${ }^{3}$ Engenheiro Agrônomo, Professor Adjunto, Departamento de Química, ESAM, Brasil. E-mail: everardo@esam.br. ${ }^{4}$ Engenheiro Agrônomo, Professor Adjunto, Departamento de Química, ESAM, Brasil. E-mail: celesmario@esam.br. ${ }^{5}$ Estudante do curso de mestrado em Agronomia: Fitotecnia, Núcleo de Pós-graduação (NPG), ESAM, Brasil. E-mail: jeanctv@hotmail.com.

${ }^{6}$ Engenheiro Agrônomo, Departamento de Química, ESAM, Brasil. E-mail: franciscleudo@hotmail.com.

${ }^{7}$ Estudante do curso de mestrado em Agronomia: Fitotecnia, NPG, ESAM, CP137, 59625-900, Mossoró, RN, Brasil.

E-mail: aureliojr02@hotmail.com.

${ }^{8}$ Estudante de Agronomia, ESAM, Brasil. E-mail: adalbertohipolito@bol.com.br. 
As perdas pós-colheita de frutas têm importante significado não só do ponto de vista econômico, como também, nutricional. Os fatores responsáveis por essas perdas são: temperatura de conservação, umidade relativa, microrganismos fitopatogênicos, condições inadequadas de armazenamento, cuidados durante o manuseio e o transporte, além do descarte de frutas não comercializáveis.

Diante deste problema, existe a preocupação em melhorar a conservação dos frutos através de diferentes métodos. A desidratação de frutas torna-se uma maneira de evitar desperdícios, pois frutos fora do padrão de mercado podem ser aproveitados sem nenhum problema. A cristalização é uma forma de industrialização feita através de tecnologias adequadas onde substituise parte da água de constituição dos frutos por açúcares, em níveis que impeçam a deteriorização (SOLER et al., 1988).

Este trabalho teve como objetivo a obtenção de melão cristalizado das variedades Gália, Pele de Sapo e Orange Fresh pelo processo lento de açucaramento.

Os melões utilizados em julho de 2001 foram provenientes da Fazenda "Shoryu", no município de Baraúnas-RN. As variedades Gália, Pele de Sapo e Orange Fresh, não são aceitas pelas normas de comercialização "In natura" tanto no mercado interno como no externo.

Após a chegada dos melões, no total de 25 por variedade, seguindo o fluxograma apresentado na figura 1 , os mesmos foram submetidos a uma lavagem, seguido de um corte ao meio, e depois a retirada de quatro amostras em forma de "bolas" com uma forma de tirar sorvete em cada parte do melão. A partir daí, teve início o processo de cristalização do melão através de um pré-tratamento que se baseou na imersão das bolinhas numa solução de $3 \%$ de cloreto de cálcio durante 30 minutos, para que ocorresse a reação do cálcio com a pectina, melhorando-se assim a rigidez da fruta. Logo após a aplicação do pré-tratamento, as bolas foram submetidas a uma solução de sacarose com $20^{\circ}$ Brix, visando reduzir o enrugamento dos frutos, e aquecidas à plena fervura. Após o aquecimento, as bolas permaneceram na solução por 24 horas para alcançar o equilíbrio osmótico. Após esse período, o xarope foi retirado, medindo-se sua concentração e adicionado-se açúcar em quantidade suficiente para elevar a concentração em $10^{\circ}$ Brix, conforme a fórmula descrita por JACKIX (1988). Na seqüência, o brix foi aferido através do refratômetro, para então o xarope ser novamente submetido à fervura e colocado sobre os frutos, deixando-se em repouso por 24 horas. Este procedimento foi repetido para soluções com 30, 40, 50, 60 e $70^{\circ}$ Brix. Alcançado o teor de equilíbrio após o último tratamento, os frutos foram retirados do xarope e colocados numa peneira para o escorrimento de calda para chegar a uma a umidade final entre 22-25\%.

Com o objetivo de verificar se houve aceitação dos produtos pelos consumidores, foi feita uma análise sensorial, utilizando-se uma escala hedônica de 09 pontos cujos limites seguem a seguinte classificação: 01 para "não gostei extremamente" e 09 para “gostei extremamente”. As amostras foram apresentadas a um painel de 10 provadores não treinados e não fumantes, sendo servidas em pratos plásticos descartáveis e divididas em lotes, segundo a metodologia recomendada por CHAVES (1980). A cada amostra provada, os provadores lavaram a boca com água destilada para evitar a influência do sabor da amostra anterior.

Os resultados das análises físicoquímicas das três variedades de melão na forma "in natura" apresentados na tabela 1 mostram o alto teor de umidade e a redução desses teores, quando a polpa foi cristalizada na forma de bolas. Verificou-se também, um aumento nos sólidos solúveis totais e na acidez total titulável e uma diminuição no pH das polpas cristalizadas. A redução do teor de umidade e o aumento do teor de sólidos solúveis totais em polpa cristalizadas na forma de bolas de melões das variedades Gália, Pele de Sapo e Orange Fresh são apresentadas na tabela l. O aumento dos valores de sólidos solúveis totais nas polpas cristalizadas, para todas as variedades, foi também observado por CAMARGO et al, (1984).

O aumento no percentual de sólidos solúveis é motivado por um aumento na concentração de sólidos naturais do melão devido à perda de água por diferença de pressão osmótica entre o fruto e a solução de açúcar e pela absorção de açúcar pelo fruto a partir da solução usada como meio de secagem osmótica. As mudanças acentuadas no teor de umidade entre as polpas do melão ao natural e as cristalizadas confirmam o efeito conservador da cristalização para frutos. Os valores finais para os teores de umidade estão em 
Fruto "in natura"

$$
\begin{gathered}
\downarrow \\
\text { Recepção }
\end{gathered}
$$

$\downarrow$

Lavagem

$\downarrow$

Corte ao meio (cada fruto)

$\downarrow$

Retirada da polpa em forma de bolas

Imersão dos frutos numa calda de cloreto de cálcio a $0,3 \%$

Aquecimento das "bolas" em soluções de sacarose com $20,30,40,50,60, \mathrm{e} 70^{\circ} \mathrm{Brix}$

$\downarrow$

Repouso em cada solução durante 24 horas

Secagem durante 6 horas

$\downarrow$

Embalagem

Figura 1 - Fluxograma básico do processamento lento de açucaramento

Tabela 1 - Características físico-químicas dos melões Gália (A), Pele de Sapo (B) e Orange Fresh (C) “in natura” e desidratado pelo processo

\begin{tabular}{|c|c|c|c|c|c|c|}
\hline \multirow{2}{*}{ Determinações } & \multicolumn{3}{|c|}{ Melão “in natura” } & \multicolumn{3}{|c|}{ Melão cristalizado } \\
\hline & A & B & $\mathrm{C}$ & A & B & $\mathrm{C}$ \\
\hline Teor de umidade (\%) & 85,54 & 85,21 & 84,98 & 27,53 & 26,21 & 26,16 \\
\hline $\mathrm{pH}$ & 6,21 & 5,84 & 6,12 & 5,60 & 5,70 & 5,76 \\
\hline Sólidos solúveis totais (\%) & 11,60 & 12,00 & 9,50 & 70,20 & 70,40 & 69,10 \\
\hline Acidez total titulável (g/100g) & 0,02 & 0,02 & 0,02 & 0,16 & 0,17 & 0,15 \\
\hline
\end{tabular}
de lento de açucaramento.

Ciência Rural, v.35, n.3, mai-jun, 2005. 
consonância com os dados da literatura, perfeitamente dentro da faixa considerada normal para frutos secos. Segundo CRUESS (1973) e CAMARGO et al. (1984), a estabilidade de tais produtos é alcançada quando a umidade residual está entre 25 a 33\% de água, que garante a conservação dos melões em temperatura ambiente, desde que acondicionados em embalagens que funcionem como boa barreira a passagem de vapor d’água. Quanto aos valores de $\mathrm{pH}$ e acidez total titulável, observa-se também que houve variações mareantes nas polpas dos melões antes e depois da cristalização (Tabela l). A acidez total titulável aumentou de 7 a 8 vezes no produto cristalizado, o que se justifica devido ao aumento da concentração dos íons $\mathrm{H}^{+} \mathrm{A}$ variação de $\mathrm{pH}$ não foi tão pronunciada, possivelmente devido a um forte poder tamponante, apresentado praticamente por todos os frutos, como também observaram TRAVAGLINI et al. (1984), trabalhando com ameixa Carmesim.

Pode-se observar que não houve perda de coloração da polpa em nenhuma das variedades. Esse fato, segundo TORREGGIANI (1993), pode ser explicado pela inativação das enzimas fenolases, que são responsáveis pelo escurecimento enzimático da fruta, e, por serem enzimas oxidases termolábeis, foram facilmente inativadas pelo calor fornecido pelo xarope. De acordo com esse mesmo autor, a alta concentração de açúcar ao redor dos pedaços de frutas também contribui para evitar a perda de cor por escurecimento enzimático.

Tomando-se como base apenas o percentual de aceitação, a variedade Pele de Sapo foi a que se destacou e teve uma ampla preferência, uma vez que $90 \%$ dos provadores avaliaram como gostei de moderadamente a muito (Tabela 2). Esse resulatado provavelmente deve-se á sua textura mais firme "in natura” e ao teor de sólidos solúveis totais superiores ao demais.
Tabela 2 - Resultados em percentagem (\%) da análise sensorial da polpa desidratada pelo processo lento de açucaramento dos melões Gália (A), Pele de Sapo (B) e Orange Fresh (C).

\begin{tabular}{lccc}
\hline Avaliação & \multicolumn{3}{c}{ Variedades } \\
\hline & A & B & C \\
Não gostei muito & --- & --- & 10 \\
Não gostei moderadamente & 10 & 10 & 20 \\
Indiferente & 20 & --- & 30 \\
Gostei moderadamente & 50 & 60 & 20 \\
Gostei muito & 20 & 30 & 20 \\
\hline
\end{tabular}

A cristalização da polpa de melões em forma de bolas mostrou-se tecnicamente viável, e a variedade Pele de Sapo destacou-se no teste de aceitação, não ocorrendo mudança na coloração da polpa das variedades.

\section{REFERENCIAS BIBLIOGRÁFICAS}

CAMARGO, R. de, et al. Tecnologia dos produtos agropecuários. São Paulo: Nobel, 1984 278p.

CHAVES, J. B. P. Avaliação sensorial de alimentos. Viçosa- MG, Universidade de Viçosa. Departamento de Tecnologia de Alimentos. 1980. 58p.

CRUESS, W. V Produtos industrializados de frutas e hortaliças. Tradutor, Heitor Airlie Tavares. São Paulo: Edgrad Blucher, 1973. Vol II. 854p.

JACKIX, M. H. Doces, geléias e frutas em caldas. Campinas: UNICAMP. 1988. 172p.

SOLER, M. P. et ai. Industrialização de frutas. Campinas- SP: ITAL. 1988. 312p.

TRAVAGLINÏ, D. A., et ai. Secagem de ameixa, cultivar carmesim: III Efeito da pré-secagem osmótica nas características organolépticas dos produtos final. Boletim do ITAL. Campinas-Sp, v. 21,n. 2, p. 157- 167, abr.-jun.1984.

TORREGGIANI, D. Osmotic dehydration in fruita nd vegetable processing. Food Research International, v 26, p 59-68, 1993 